\title{
Realidade sociopolítica, ambiental e de saúde de famílias pertencentes a uma comunidade vulnerável
}

\author{
The social-political-environmental and health reality \\ of families belonging to a vulnerable community
}

Carla Kowalski Marzari ${ }^{1}$ Dirce Stein Backes ${ }^{1}$ Marli Stein Backes ${ }^{2}$ Mara Teixeira Marchiori ${ }^{1}$ Martha Teixeira de Souza ${ }^{1}$ Adriana Dornelles Carpes ${ }^{1}$
${ }^{1}$ Centro Universitário Franciscano (Unifra). R. dos Andradas 1614, Centro. 97010-032 Santa Maria RS. carlamarzari@hotmail.com ${ }^{2}$ Hospital Escola, Universidade Federal de Pelotas (UFPel).

\begin{abstract}
The scope of this paper is to ascertain the perception of community leadership, health professionals and users regarding citizenship status and the enhancement of the healthcare conditions of families belonging to a vulnerable community. This is an exploratory study of a qualitative nature, guided by theory based on data. Data were collected between July and December 2009, by means of interviews with four community health leaders, a team of eight family health team professionals and twelve health users. The codification of the data resulted in the following categories: Understanding the social conditions, the political conditions, the environmental conditions and the health conditions of families in a vulnerable community. The conclusions reached were, that if on the one hand the social security and health policies made it possible to reduce poverty and local inequalities, on the other hand they do not ensure the requisite enhancement of citizenship or even the improvement of health conditions.
\end{abstract}

Key words Nursing research, Unified Health System, Family Health Program, Primary Healthcare Unit
Resumo Objetivo: Conhecer a percepção de lideranças, profissionais de saúde e usuários acerca da cidadania e melhoria das condições de saúde de famílias pertencentes a uma comunidade vulnerável. Método: Estudo exploratório, de caráter qualitativo, orientado pela teoria fundamentada nos dados. Os dados foram coletados entre julho e dezembro de 2009, mediante entrevistas com quatro lideranças comunitárias de saúde, oito profissionais de uma equipe de saúde da família e doze usuários da saúde. Resultados: A codificação dos dados resultou nas categorias: Compreendendo as Condições sociais, as Condições políticas, as Condições ambientais e as Condições de saúde de famílias de uma comunidade vulnerável. Conclusões: Se por um lado as politicas de seguridade social e de saúde possibilitaram a redução da pobreza e das desigualdades locais, por outro lado, não garantem a necessária expansão da cidadania e nem mesmo a melhoria das condições de saúde.

Palavras-chave Pesquisa em enfermagem, Sistema Único de Saúde, Programa Saúde da Família, Unidade Básica de Saúde 


\section{Introdução}

A construção do Sistema Único de Saúde (SUS) prevista na Constituição Brasileira de 1988 é resultado de um processo de lutas coletivas. Considerado o maior movimento de inclusão social já visto na História do Brasil, o SUS representa, em termos constitucionais, uma afirmação política de compromisso do Estado brasileiro para com os direitos dos seus cidadãos ${ }^{1}$. Além de ser único, descentralizado e universal, incorporou os três níveis de governo, constituindo-se, assim, num sistema amplo e complexo, isto é, em um dos sistemas de maior cobertura do país ${ }^{2}$.

Com o SUS, emergiram também as Unidades de Saúde da Família, assim denominadas por estarem localizadas em pontos estratégicos da comunidade e por atenderem uma determinada área de abrangência populacional. Nessa perspectiva, a tradicional área geográfica, passou a ganhar novos significados pela superação da ideia de espaço geográfico simétrico. A partir de uma nova concepção teórico-prática, a visão de território-processo passa a caracterizar-se como um espaço de vida pulsante, o qual considera não apenas os determinantes quantificáveis do binômio saúde-doença, mas também os condicionantes do entorno, isto é, as condições econômicas, políticas, culturais e sanitárias de cada comunidade e família em particular ${ }^{3}$.

A ideia de território-processo impulsionou, sob esse enfoque, um movimento de superação do tradicional conceito saúde-doença, no qual a comunicação socialmente relevante era a doença e não a saúde. Igualmente, impulsionou a superação do conceito de saúde demandada nos muros de um "Posto de Saúde", no qual se privilegiava o modelo biomédico reducionista, com foco em práticas prescritivas e assistencialistas ${ }^{3}$.

Além disso, permitiu o desenvolvimento de vínculos entre os serviços de saúde, orientados por categorias de análise de cunho geográfico. Esse reconhecimento é realizado através da observação das condições de cidadania, criadas no espaço para a produção, a circulação, a residência, a comunicação para o exercício da política e das crenças para o lazer e como condição de vida ${ }^{4}$.

Pautada em princípios e diretrizes do SUS, a Estratégia Saúde da Família (ESF) vem se constituindo como uma prática substitutiva às tradicionais práticas de saúde, além de respaldar-se em princípios norteadores como a integralidade da assistência, a equidade no atendimento e a participação da comunidade, os quais se articulam com o controle social. A ESF está ancorada, tam- bém, em diretrizes como a intersetorialidade das ações e a territorialização da área de abrangência, a partir de vínculos efetivos com a família e a comunidade 5 .

Enquanto política universal de saúde, o SUS, por meio da ESF, tem a possibilidade de promover a cidadania, bem como, reduzir a pobreza e a desigualdade social de famílias, sobretudo em comunidades vulneráveis, aqui entendidas como aquelas que vivenciam influências ambientais, econômicas, políticas e culturais que enfraquecem as relações, as interações e as associações individuais, familiares e sociais ${ }^{5,6}$. Sendo assim, questiona-se: qual a percepção de lideranças, profissionais de saúde e usuários acerca da cidadania e melhoria das condições de saúde de famílias pertencentes a uma comunidade vulnerável?

Com base no exposto, o presente estudo teve por objetivo conhecer a percepção de lideranças, profissionais de saúde e usuários acerca da cidadania e melhoria das condições de saúde de famílias pertencentes a uma comunidade vulnerável.

\section{Metodologia}

Trata-se de uma pesquisa exploratória, de caráter qualitativo, orientada pela teoria fundamentada nos dados ${ }^{7}$.

A pesquisa foi realizada em uma comunidade vulnerável, constituída por aproximadamente vinte e cinco mil habitantes, sendo que muitas famílias se encontram em situação de extrema pobreza. Nesse local, está inserido, atualmente, um núcleo de projetos de Ensino, Pesquisa e Extensão vinculados ao Centro Universitário Franciscano (UNIFRA), os quais são realizados em parceria com a Prefeitura Municipal do referido município.

Para conhecer a comunidade, foi realizado, inicialmente, um mapeamento, isto é, um "Mapa vivo" da comunidade coberta pela ESF, no sentido de se obter informações específicas da realidade local, bem como compreender a atuação do enfermeiro neste local específico. Para obter os dados de pesquisa, foram realizadas entrevistas com lideranças comunitárias (quatro), profissionais que integram uma equipe ESF (oito) e usuários de saúde (doze), totalizando 24 participantes. Os profissionais da ESF foram selecionados a partir da escala de trabalho e os usuários de saúde através das fichas cadastrais armazenadas no arquivo da unidade local de saúde; e as lideranças comunitárias foram indicadas pelos profissionais da ESF. Ainda, foram coletadas informações com- 
plementares em documentos e relatórios oficiais da Unidade Básica local e Secretaria Municipal de Saúde de Santa Maria (RS), Brasil. Os dados foram coletados, por meio de questões norteadoras, pelos próprios pesquisadores no período de julho a dezembro de 2009, em dias, horários e local previamente agendado. E após, foram coletados e codificados conforme pressupostos da teoria fundamentada nos dados.

Os aspectos éticos em relação à pesquisa com seres humanos foram observados, de acordo com as recomendações da Resolução do Conselho Nacional de Saúde do Brasil no 196/968 e o projeto foi aprovado pelo Comitê de Ética em Pesquisa da UNIFRA.

As falas dos participantes, ao longo do texto, foram identificadas com a letra "L" (lideranças), "P" (profissionais) e "U” (usuários), seguida de um número correspondente à fala, a fim de manter o anonimato dos mesmos.

\section{Resultados e discussão}

Os dados organizados e codificados resultaram em quatro categorias temáticas, quais sejam: Compreendendo as condições sociais; Compreendendo as condições políticas; Compreendendo as condições ambientais e Compreendendo as condições de saúde, as quais são descritas e discutidas, a seguir.

\section{Compreendendo as condições sociais}

Anteriormente à Constituição Brasileira de 1988, os direitos sociais, em especial os da previdência e da saúde, eram garantidos aos trabalhadores sem a devida relação entre os direitos sociais e a cidadania plena. A noção de cidadania, até então, estava praticamente ausente do imaginário e dos valores da população. A partir daí, foram reconhecidos como direitos sociais o acesso à: saúde, previdência, assistência, educação e moradia, além de segurança, lazer e trabalho. $\mathrm{O}$ desenvolvimento da atenção integral à família tem sido um dos pontos da agenda para o desenvolvimento social ${ }^{9}$.

Esta realidade, todavia, está longe de ser concretizada plenamente, principalmente nos espaços mais vulneráveis da sociedade brasileira. O levantamento de informações da comunidade permite-nos afirmar que ainda há um longo caminho a ser trilhado, no sentido de alcançar o pleno exercício da cidadania, na qual todos têm direitos comuns e universais, ou seja, a compreensão do que é cidadania e direitos universais.
A comunidade mapeada constitui-se de um assentamento de famílias, as quais são provenientes de diferentes municípios do estado do Rio Grande do Sul. Cada família possui, em média, quatro filhos e renda mensal abaixo de um salário-mínimo. Cerca de $90 \%$ das famílias são beneficiadas pelo Programa Bolsa Família, criado pelo Governo Federal, a fim de complementar a renda das famílias que se encontram em condições vulneráveis.

O Programa Bolsa Família é de âmbito nacional e beneficia famílias que possuem renda mensal per capita de R \$70,00 a R\$ 140,00 ou em extrema pobreza (com renda mensal inferior a $\mathrm{R} \$$ 70,00 ), iniciativa assegurada pela Lei $\mathrm{n}^{\circ} .10 .836$ de 09/01/2004 ${ }^{10}$, e Decreto no 5.209 de 17/09/ $2004^{11}$. O Bolsa Família beneficia, atualmente, mais de 11 milhões de famílias brasileiras, servindo de estímulo, mais especificamente, para manter as crianças e os adolescentes na escola ${ }^{12}$. Para tanto, foram criadas Câmaras Intersetoriais Permanentes de Políticas Sociais, coordenadas por secretários municipais e subordinadas ao prefeito, que discutem e reúnem questões de saúde, educação e assistência social para o acompanhamento do Programa.

Além da bolsa mensal, $50 \%$ das famílias possuem uma renda complementar por meio do trabalho temporário de um dos progenitores, os quais, na sua maioria, atuam como catadores de lixo, serventes de pedreiro e, no caso das mulheres, como empregadas domésticas, sem carteira assinada, conforme evidenciam as falas abaixo:

Quando 'pinta' um trabalho, eu faço... mas nada fixo... uma faxina aqui, outra ali... nunca consegui carteira assinada (U2; U4; U7; U11).

Fico em casa cuidando das crianças... meu marido, às vezes, consegue uns bicos fazendo serviço de pedreiro... enquanto 'dá', vamos levando (U5; U9).

Com aproximadamente vinte anos de assentamento, as famílias demonstraram e relataram uma trajetória de lutas e enfrentamentos políticos e sociais. Percebe-se, no entanto, que apesar das conquistas coletivas já alcançadas, as famílias, na sua grande maioria, não possuem uma vida social ativa e participativa, visto que passam os dias no anonimato e isolamento social e, por que não dizer, alienadas à realidade. Ficou evidente tanto na fala das lideranças, como na dos usuários que os primeiros anos de assentamento foram marcados por grandes necessidades: inexistência de luz, água, saneamento básico, bem como serviços de atendimento local. Neste período inicial, as famílias foram auxiliadas e apoiadas em suas lutas por um padre que morava na região. 
Quando vim para cá, ainda eram poucas famílias... vinham de todos os lugares... O que tínhamos em comum, era a vontade de ter um lugar próprio para morar... mas era muito difícil, não tinha água, luz e, muitas vezes, faltava também a comida, mas nunca desistimos (U2).

As condições sociais podem ser caracterizadas, em geral, como limitadas e restritas pelo aglomeramento populacional, dificuldades de acesso, alto índice de desemprego, uso de drogas ilícitas, tráfico de crianças e outros agravantes sociais, que contribuem para que a população alvo fique cada vez mais à margem da sociedade.

A fala dos entrevistados aponta para a inexistência de áreas ou espaços de lazer e convivência nesta comunidade, fato este que contribui para o isolamento social das famílias e, talvez, para o aumento do índice de usuários de drogas e da violência local.

O Brasil comemorou recentemente o alcance, com antecipação, das metas do milênio de redução da pobreza. De acordo com os dados da Pesquisa Nacional por Amostra de Domicílios do Instituto Brasileiro de Geografia e Estatística (IBGE), o índice de brasileiros vivendo na extrema pobreza caiu de $8,8 \%$ para $4,2 \%$ nos últimos cinco anos. Tomando como base o salário-mínimo, a taxa de pobreza extrema caiu de $28 \%$ para $16 \%$ da população e a de pobreza caiu de $52 \%$ para $38 \%$. Quanto à desigualdade, os dados indicam que entre 2001 e 2005, a renda dos $10 \%$ mais pobres cresceu a uma taxa anual de $9,2 \% \mathrm{e}$ a dos $10 \%$ mais ricos caiu $0,4 \%$ por ano ${ }^{13}$.

Estes dados, porém, se comparados com a realidade estudada se expressam de forma incipiente. Evidenciou-se, que as famílias vivendo em situação de extrema pobreza mantiveram os mesmos indicadores, além do aumento crescente das taxas de desemprego e, consequentemente, o aumento do uso das drogas ilícitas, violência e outros agravantes sociais.

\section{Compreendendo as condições políticas}

As condições políticas da comunidade estudada estão fortemente condicionadas ao possível favoritismo político, isto é, à política partidária ou ao partido político municipal vigente. Desse modo, as melhorias locais estão condicionadas aos interesses e/ou à vontade daqueles que se encontram no poder, como bem expressa uma das lideranças locais: $O$ difícil é quando muda o prefeito. Se o novo prefeito é de outro partido, então tudo piora... mudam os funcionários, tudo muda, precisa começar tudo de novo... (L2).
A fala dos usuários e lideranças sinaliza que o governo municipal, às vezes, não está muito empenhado em solucionar os problemas e as necessidades da população. Por estes e outros motivos, alguns integrantes se uniram e buscaram apoio junto ao governo do Estado, o qual, recentemente, regularizou a área geográfica, repassando-a ao município, conforme evidencia o enunciado jornalístico, a seguir:

Depois de quase duas décadas de espera, uma antiga reivindicação da comunidade virou realidade. ... A doação da área ao município e a assinatura da escritura pela governadora viabilizará a regularização fundiária do loteamento... a governadora assinou a transferência da área de 254 hectares da Nova Santa Marta do governo do Estado ao município, que beneficiará diretamente cerca de 5,5 mil famílias. O repasse representa a maior regularização fundiária da América Latina e permitirá o reassentamento de 30 mil moradores... ${ }^{14}$

Outro programa de governo que vem beneficiando a comunidade é o Programa de Aceleração do Crescimento. Trata-se de um programa do Governo Federal brasileiro, lançado em 28/ 01/2007, que engloba um conjunto de políticas econômicas, planejadas para o período de 2007 2010, que tem como objetivo acelerar o crescimento econômico do Brasil, prevendo investimento total de 503 bilhões de reais até $2010^{13}$.

No município em questão, os recursos deverão ser aplicados para a construção de áreas de lazer, centros comunitários, unidades habitacionais, infraestrutura urbana, recuperação ambiental, ações sociais, pavimentação e regularização fundiária em diversas vilas e bairros da cidade ${ }^{14}$.

De outro modo, ficou evidente que os moradores não possuem uma cultura política de inserção e participação na dinâmica da comunidade. Poucos moradores participam ativamente do Conselho Local de Saúde e demais movimentos em defesa da melhoria das condições locais. A mobilização e a articulação comunitária estão quase que exclusivamente, centradas nas lideranças locais que, por sua vez, também se encontram em situação vulnerável.

Além das dificuldades locais já apresentadas, os moradores mencionam a falta de escolas para os seus filhos estudarem e/ou continuarem os seus estudos, principalmente, escolas de ensino médio. Assim, por mais que as famílias demonstrem grande interesse na continuidade dos estudos por parte de seus filhos num nível secundário e/ou terciário, elas não têm condições de acesso e nem possibilidades de arcar com o deslocamento até o centro da cidade. Essa situação con- 
tribui significativamente para o aumento do uso de drogas ilícitas, bem como da violência local e regional. Ademais, destaca-se a discriminação social, visto que a região é rotulada como "região pobre" e, por isso, automaticamente vinculada ao tráfico de drogas, à marginalidade, à violência e a outros, conforme evidenciam nas falas:

Aqui, temos escolas só até o final do primeiro grau... se 'queremos' que os nossos filhos 'continuam' estudando, eles precisam ir até o centro. Mas, quem tem dinheiro para tanto ônibus e mais, eles chegam lá e são deixados de lado porque são desta região. Então, as oportunidades são muito limitadas (U10).

Queremos mais estudos para nossos filhos. Aqui tem escolas boas, mas quando termina o primeiro grau, termina tudo... eles acabam desistindo de estudar e vão trabalhar por aí para sobreviverem. $O$ maior sonho da minha filha é ter uma profissão... Ela sonha em fazer uma faculdade (U 12).

Se, por um lado, as condições políticas têm repercussões negativas neste local, por outro, é preciso concordar com autores que salientam que já existem políticas progressistas, mesmo que com restrições importantes na cobertura, no financiamento e na qualidade da atenção, ainda com baixo impacto na construção da cidadania social prevista. Em outras palavras, as políticas públicas brasileiras ainda não têm alterado o quadro de pobreza e exclusão de expressiva parcela da população ${ }^{15}$.

\section{Compreendendo as condições ambientais}

Mesmo localizado em região privilegiada do município, a comunidade em questão apresenta importantes problemas ambientais, os quais podem ser observados sem grande esforço. As residências encontram-se desordenadas e construídas muito próximas umas das outras, sem condições mínimas de conforto e segurança. Além de precárias, as casas ou "casebres" são pequenos para o número de pessoas que nelas residem. Verificaram-se, nas casas, a inexistência de forro, iluminação, ventilação e instalações hidráulicas. É comum o fato de muitas famílias agruparem-se no mesmo terreno, a fim de otimizar o espaço físico e facilitar as interações entre os membros da família, as quais são bastante intensas e afetuosas, na maioria dos casos.

Além das condições precárias das moradias, foram evidenciados problemas tais como: animais dentro das casas; saneamento básico ineficiente e inadequado; acondicionamento impróprio do lixo, o qual permanece a céu aberto; es- tradas em péssimas condições; circulação livre de animais nas ruas que, em muitos casos, contribuem na proliferação de doenças, como reflete a fala a seguir:

Tem muito cachorro e cavalo solto na rua, passando doenças para as crianças... quando a gente precisa trabalhar e deixar as crianças sozinhas, sempre fico muito preocupada. Não se sabe se elas estão na escola ou na rua, no meio da sujeira... não tem como controlar (U8).

As condições ambientais também estão relacionadas à falta de áreas próprias para o lazer e diversão. Pela proximidade das casas, não há reflorestamento ambiental, cultivo de plantas frutíferas, flores e outros que, além de contribuírem para a renovação do ar atmosférico, também, contribuem para um ambiente mais agradável e atraente. Na fala de uma das usuárias ficou evidente que a única área verde que existe nesta região é, atualmente, utilizada pelos adolescentes para cheirar crack à noite. Logo, inexistem políticas públicas, até o momento, comprometidas com a melhoria das condições ambientais.

Nessa direção, corrobora-se com estudiosos, ao mencionarem que as questões ambientais ultrapassaram os limites da Biologia, transitando do campo estrito das ciências naturais para o campo social e da saúde. A depressão grave, a esquizofrenia e outros distúrbios de comportamento parecem brotar de uma deterioração paralela de nosso meio ambiente natural e social ${ }^{16}$.

\section{Compreendendo as condições de saúde}

O Rio Grande do Sul é um estado que apresenta um dos maiores níveis de expectativa de vida do Brasil. A qual, ao nascer, passou de 63,6 anos em 1971 para 69,2 anos em 2004 para os homens. Já para as mulheres, os valores passaram de 70,0 anos em 1971 para 77,4 anos em 2004. Esses aumentos devem-se principalmente à redução da mortalidade infantil, mas também pela melhora das condições sanitárias, pela maior cobertura vacinal, a prevenção de doenças e o maior acesso aos serviços de saúde ${ }^{13}$. Apesar da melhora no nível de expectativa, permanecem, entretanto, problemas de saúde de difícil resolução. Além da falta de resolutividade e continuidade, percebem-se problemas de iniquidade no acesso e na utilização de serviços, ainda bastante vinculado à condição social e geográfica, com tímida redução das desigualdades, apesar dos investimentos nas Unidades Locais de Saúde e atuação da equipe de ESF. Sabe-se que, com a ampliação das ESF no Brasil, surgem outros atores 
sociais que produzem expectativas em amenizar as mazelas das demandas sociais. Os agentes de saúde assumem responsabilidades em comunidades como tática de elencar as dificuldades vividas, conferindo assim complexidade ao trabalho, por exigir uma síntese entre a dimensão social e de saúde da população ${ }^{17}$.

Evidenciou-se, que o modelo de saúde vigente ainda está fortemente centrado na doença ou medicalização da doença, apesar das medidas de reorientação que vem se intensificando com a consolidação da ESF. As doenças que se apresentam em escala crescente são a hipertensão, o diabetes e a depressão. As principais dificuldades de saúde apontadas pelos moradores foram a falta de profissionais de saúde, principalmente de agentes comunitários; e a dificuldade de acesso aos serviços de alta complexidade em saúde.

Além das doenças tradicionalmente reconhecidas, foram evidenciados agravos sociais sérios, os quais acometem diretamente o viver saudável das pessoas e para os quais ainda não foram delineadas medidas efetivas. Os entrevistados, em geral, expressaram grande preocupação com os usuários de drogas (principalmente, com os de crack, os quais vêm crescendo assustadoramente no povoado), bem como a violência contra as mulheres e crianças e a prostituição infantil.

O que mais aparece aqui na Unidade Básica é a depressão... tem muitas mulheres deprimidas que não conseguem trabalhar, pois tem que cuidar dos filhos... ficam sem dinheiro para manter a casa. $O$ companheiro joga fora o pouco que tem em bebidas, drogas... Então, elas acabam ficando com depressão (P3).

Tem muitas crianças aqui nesta comunidade... a gente percebe que muitas vivem tristes, sem perspectivas... quando vamos investigar mais a fundo, percebemos que elas sofrem algum tipo de violência... ou em casa, ou na escola, ou na rua mesmo... (P5).

Estudo anteriormente realizado, já evidenciou que a comunidade em questão, apresenta o maior número de ocorrências de violência contra a mulher no município, o que sugere uma associação com áreas tradicionalmente mais carentes, ou seja, com áreas que se encontram em maior vulnerabilidade social ${ }^{18}$

As mulheres da comunidade, além de estarem comprometidas com os filhos, isto é, com a amamentação, cuidados de higiene e alimentação, passam a ter também a responsabilidade com os cuidados domésticos em geral. Os homens, mesmo que em número reduzido, são os provedores do sustento diário. Muitas mulheres, no entanto, vi- vem sem a presença do companheiro, o que dificulta ainda mais suas vidas. Além de buscarem o sustento mediante um trabalho informal. Nessa direção, essa realidade complexa e multifacetada exige a composição de olhares e saberes diversos e igualmente complexos. Essa visão poderá ser enriquecida e evoluída na medida em que se colocar em prática um conceito mais ampliado de saúde, capaz de compreender o processo saúde-doença como inseparável do desenvolvimento econômico, político e social ou em congruência a esse, um conceito de território-processo pulsante que considera a cidadania, a participação e a responsabilização coletiva, em conduzir e motivar os diferentes setores e atores sociais para uma atitude ativa e associativa, no que diz respeito às questões de saúde. Logo, é preciso concordar com estudos que convocam os profissionais para a articulação e a interação entre os diversos setores, no que se refere ao planejamento, à execução e ao monitoramento de intervenções para enfrentar problemas complexos/necessidades específicas de grupos populacionais, como as abordadas neste estudo $^{19}$.

Já os profissionais que integram a equipe da ESF, reconhecem a necessidade da atuação integrada entre as várias áreas e saberes profissionais e, mais do que isso, a falta de integração como uma causa importante da baixa efetividade nos serviços de saúde locais. Reconhecem que o SUS, na forma como foi concebido, deveria ser um exemplo para o mundo, sendo um sistema único, organizado, integrado e qualificado. No entanto, necessita de gestão responsável e vontade política, a fim de garantir a continuidade e a resolutividade dos cuidados em saúde.

Quanto à opinião dos integrantes acerca do trabalho da equipe da ESF, os mesmos reconhecem e salientam de modo especial a atuação do agente comunitário de saúde. Este pensar pode ter sido influenciado pelo fato de os agentes comunitários estarem no programa há mais tempo, sendo que os demais profissionais da equipe haviam sido contratados recentemente. Evidencia-se, também, que o agente de saúde consegue, na maioria dos casos, estabelecer um vínculo efetivo com as famílias e, dessa forma, mediar as diferentes situações com a equipe de saúde local.

A equipe tem feito um esforço, juntamente com acadêmicos dos cursos da área da saúde da UNIFRA, no sentido de ampliar ações de promoção da saúde através da formação de grupos de convivência de mulheres, idosos, crianças e puericultura. Nesses grupos, os debates giram em torno de temas solicitados pelos participan- 
tes que, frequentemente, recaem sobre problemas sociais como o exercício da cidadania e a geração de renda como forma de buscar a autonomia. As reuniões dos grupos são realizadas em espaços da própria comunidade, em Igrejas e em casas de moradores.

Apesar do movimento crescente de busca de articulação ou organização desta comunidade como tal, com avanços e retrocessos, ainda se encontra com pouca articulação social e política, condições de vida em pobreza, marginalidade, violência, saúde precária, dentre outros.

\section{Considerações finais}

A percepção de lideranças, profissionais de saúde e usuários acerca da cidadania e melhoria das condições de saúde de famílias pertencentes a uma comunidade vulnerável, permite argumentar que, se por um lado as políticas de seguridade social e as políticas de saúde possibilitaram a redução da pobreza e das desigualdades locais, por outro lado ainda não garantem a necessária expansão da cidadania e nem mesmo a melhoria das condições de saúde.

As categorias encontradas: Compreendendo as condições sociais, as Condições políticas, as Condições ambientais e as Condições de saúde em uma comunidade vulnerável, demonstram uma realidade de pobreza e exclusão social, mesmo contando com as políticas de atenção do SUS, com equipe de ESF e políticas sociais do âmbito nacional, regional e local.

O Brasil tem feito esforços importantes para mudar o padrão tradicional de tratamento dos problemas sociais e de saúde ao implementar a Estratégia Saúde da Família e, dessa forma, contribuir para um melhor acesso às necessidades básicas de saúde. Porém, as comunidades vulneráveis ainda convivem com a baixa cobertura assistencial, acesso precário, descontinuidade, falta de resolutividade nos serviços de saúde e frágil integração intersetorial.

Em relação à concepção do desenvolvimento social, como da construção do aparato político e organizacional, é possível identificar avanços importantes, mas o ritmo em que avançam e a dinâ- mica resultante de sua interação apresentam entraves importantes que, geralmente, deslizam em questões político-partidárias. Nessa direção, a seguridade social deve ser mais do que o guardachuva que garante recursos vinculados a sistemas estruturados de serviços e benefícios, para ser a referência do pensar e atuar na proteção, sobretudo, nos espaços sociais mais vulneráveis. É preciso recuperar o lugar das políticas universais e dotá-las de financiamento e estrutura adequados, articulando-as com as políticas econômicas, ambientais e de saúde. Não há desenvolvimento humano em contextos de profunda desigualdade como a realidade aqui estudada, sem políticas universais que promovam a seguridade social, a educação, a habitação e a distribuição de renda.

Assim, a cidadania, a participação e a responsabilização coletiva, vêm ao encontro a conduzir e a motivar os diferentes setores e atores sociais para uma atitude ativa e associativa, cujo centro é o ser humano como um ser singular e social, de modo que o individual e o coletivo sejam a expressão de um todo indissociável.

\section{Colaboradores}

CK Marzari, DS Backes, MS Backes, MT Marchiori, MT Souza e AD Carpes participaram igualmente de todas as etapas de elaboração do artigo. 


\section{Referências}

1. Brasil. Ministério da Saúde (MS). Conselho Nacional de Secretários de Saúde. Sistema Único de Saúde. DF: MS; 2007. (Coleção Progestores - Para entender a Gestão do SUS, 1).

2. Silva AM, Oliveira MSM, Nunes EFPA, Torres ZM. A Unidade Básica de Saúde e seu território. In: Andrade SM, Soares DA, Cordoni Júnior L, organizadores. Bases da Saúde Coletiva. Londrina: Ed. UEL; 2001. p. 268.

3. Chiesa AM, Kon R. Compreensão do território: instrumento de gestão em atenção primária à saúde. In: Santos AS, Miranda SMR, organizadores. A enfermagem na gestão em atenção primária à saúde. Barueri: Manole; 2007.

4. Monken M, Barcellos C. Vigilância à saúde e território utilizado: possibilidades teóricas e metodológicas. Cad Saude Publica 2005; 21(3):898-906.

5. Escorel S, Giovanella L, Mendonça MHM, Senna MCM. O Programa de saúde da família e a construção de um novo modelo para a atenção básica no Brasil. Rev Panam Salud Publica 2007; 21(2/3):164176.

6. Grupo de Estudos e Pesquisa em Empreendedorismo Social da Enfermagem e Saúde (GEPESES). Validação de conceito de comunidade vulnerável na perspectiva da complexidade. Conceito discutido e validado no grupo de pesquisa. Santa Maria (RS): GEPESES; 2011.

7. Strauss A, Corbin J. Bases de la investigación cualitativa. Técnicas y procedimientos para desarrollar la teoría fundamentada. Medelin: Universidad de Antioquia; 2002.

8. Brasil. Ministério da Saúde (MS). Conselho Nacional de Saúde. Resolução no 196 de 10 de outubro de 1996. Diretrizes e Normas Regulamentadoras de Pesquisas Envolvendo Seres Humanos. Diário Oficial da União 1996; out 16.

9. Brasil. Ministério da Saúde (MS). Secretaria de Atenção à Saúde. Departamento de Atenção Básica. Política nacional de atenção básica. Brasília (DF): MS; 2006.

10. Brasil. Lei no 10.836 de 9 de janeiro de 2004. Cria o Programa Bolsa Família e dá outras providências. Diário Oficial da União 2004; jan 12.

11. Brasil. Decreto no 5.209 de 17 de setembro de 2004 Regulamenta a Lei no 10.836 , de 9 de janeiro de 2004, que cria o Programa Bolsa Família, e dá outras providências. Diário Oficial da União 2004; set 20.
12. Brasil. Ministério do Desenvolvimento Social e combate à fome. Programa Bolsa Família. [acessado 2009 dez 19]. Disponível em: http://www.mds.gov.br/ bolsafamilia/o_programa_bolsa_familia/principaisresultados/

13. Instituto Brasileiro de Geografia e Estatística (IBGE). Pesquisa Nacional por Amostra de Domicílios. Acesso a transferência de renda e programas sociais 2006. Rio de Janeiro: IBGE; 2008.

14. Schirmer C. Fim da espera de quase duas décadas: área da Nova Santa Marta é do município. Publicado em 24/09/2009. [acessado 2009 dez 28]. Disponível em: www.santamaria.gov.br

15. Nora H, Berta MC. Família e proteção social: na prática a teoria é outra. Rev Temas sociais em ex pressão 2005; 4(4).

16. Batista RS, Rôças G, Gomes AP, Albuquerque VS Araújo FMB, Messeder JC. Ecologia na formação do profissional de saúde: promoção do exercício da cidadania e reflexão crítica comprometida com a existência. Revista brasileira de educação médica 2009; 33(2):271-275.

17. Marzari CK, Junges JR, Selli L. Agentes comunitários de saúde: perfil e formação. Cien Saude Colet 2011; 16(1):873-880.

18. Souza M. Geoinformação aplicada à saúde pública: avaliação dos casos de violência contra a mulher no município de Santa Maria, RS [tese]. Santa Maria: Universidade Federal de Santa Maria; 2008.

19. Costa CR, Fracolli LA, Chiesa AM. Desafios para o trabalho do enfermeiro no PSF/PACS nas grandes metrópoles: análise da gerência. In: Santos AM, Miranda SM, organizadores. A enfermagem na gestão em atenção primária à saúde. Barueri: Manole; 2007.

Artigo apresentado em 01/03/2012

Aprovado em 27/04/201

Versão final apresentada em 04/05/2012 